\title{
EXPECTATIVA PELA ADAPTAÇÃO DA LITERATURA CINQUENTA TONS MAIS ESCUROS PARA A TELONA: uma análise da fanpage Cinquenta Tons
}

\begin{abstract}
COSTA, Thaiga Larissa da ${ }^{1}$ COSTA, Barbara Regina Lopes $\mathrm{da}^{2}$ ARAÚJO, Richard Medeiros de ${ }^{3}$

RESUMO: Com o lançamento do primeiro filme da trilogia Cinquenta Tons de Cinza, em 2014, os fãs criaram a expectativa de como seria o segundo filme, denominado Cinquenta Tons Mais Escuros. Para trocar informações e acompanhar o desenvolvimento das gravações, elenco e bastidores do filme, os fãs começaram a seguir páginas nas redes sociais virtuais, mais especificamente as Fanpages do Facebook. O objetivo principal deste estudo foi verificar a expectativa dos fãs em relação ao lançamento do filme, identificar as cenas mais esperadas, entender o público alvo e analisar a aprovação/reprovação dos atores escolhidos para cada personagem do filme. Para isso, foi necessário fazer uma pesquisa de campo por meio de observação, especificamente na Fanpage Cinquenta Tons de Cinza, página que no período analisado, de janeiro a junho de 2016, continha mais de 1.700 .000 curtidas. Com base nas postagens feitas na Fanpage, constatou-se que a expectativa dos fãs era de interesse no lançamento do filme e os atores escolhidos foram parcialmente aprovados. Por fim, verificou-se que os fãs acreditavam que Cinquenta Tons Mais Escuros seria mais fiel à obra literária, com mais cenas quentes, inclusive de sexo.
\end{abstract}

Palavras-chave: Cinquenta Tons Mais Escuros. Expectativas. Fanpage.

SUMMARY: With the release of the first film in the trilogy Fifty Tons of Gray in 2014, fans created the expectation of what would be the second film, called Fifty More Dark Tones. To exchange information and track the development of the film's footage, cast and backstage, fans have begun following pages on virtual social networks, more specifically Facebook Fanpages. The main objective of this study was to verify the fans' expectations regarding the film's release, identify the most anticipated scenes, understand the target audience and analyze the approbation $/$ disapproval of the chosen actors for each character in the film. For this, it was necessary to do a field research through observation, specifically in the Fanpage Fifty Tons de Cinza, page that in the analyzed period, from January to June of 2016, contained more than 1,700,000 tanned. Based on Fanpage posts, it was found that the fans' expectations were of interest in the release of the film and the chosen actors were partially approved. Finally, it turned out that fans believed that Fifty Darkest Tones would be more faithful to the literary work, with more hot scenes, including sex.

Keywords: Fifty Shades Darker. Expectations. Fanpage.

\section{INTRODUÇÃO}

A trilogia Cinquenta Tons foi baseada em outra obra literária - Crepúsculo, mas Erika Leonard James escreveu a sua própria estória, substituindo o mundo de fantasia dos vampiros e lobos pelo mundo real, com problemas psicológicos e sexuais.

A estória começou a ganhar vida através de uma página da internet, conhecidas como fanfiction ${ }^{4}$. Em 2011, uma editora australiana comprou os direitos de publicação (CARDOSO, 2013) e, em maio do mesmo ano, foi lançado o primeiro volume Cinquenta Tons de Cinza, seguido pelos outros dois livros

\footnotetext{
${ }^{1}$ Administradora pela FAESN

2 Doutor em Administração pelo PPGA/UFRN - UFRN/UNIFACEX

${ }^{3}$ Doutora em Administração pela UDE - Universidad de la Empresa/Uruguai

${ }^{4}$ Fanfiction são 'ficções de fãs', são histórias criadas por fãs baseadas nas já existentes de determinado livro, filme, história em quadrinhos ou quaisquer outros meios de comunicação.
} 
livros da série, Cinquenta Tons Mais Escuros e Cinquenta Tons de Liberdade, que complementam a estória.

Em 2012, a trilogia apareceu na lista de best sellers do The New York Times, durante 100 semanas, e em 2014 atingiu a marca de 100 milhões de cópias vendidas mundialmente (O GLOBO, 2014). Com o sucesso de vendas, a Universal Pictures enxergou uma possível adaptação da literatura para filme e comprou os direitos da obra, em março de 2012.

O primeiro filme da trilogia foi lançado nos EUA, no dia 13 de fevereiro de 2015, data em que se comemorava o dia dos namorados no país, sendo que no Brasil foi antecipado para o dia 12 de fevereiro. O segundo filme, Cinquenta Tons Mais Escuros, estreou nas telonas dos EUA em 10 de fevereiro de 2017 e o terceiro, Cinquenta Tons de Liberdade, em 09 de fevereiro 2018.

A adaptação da obra Cinquenta Tons de Cinza para o cinema teve-se grande repercussão nas redes sociais virtuais - RSV e gerou expectativas com o lançamento dos demais filmes da série. $\mathrm{O}$ filme Cinquenta Tons de Cinza deixou a desejar nas cenas que não foram fiéis à obra literária, obtendo, assim, um número considerável de críticas, em relação às cenas que foram julgadas "mornas" (MENDES, 2015), (MORAES, 2017). Atenta às críticas, a Universal Pictures anunciou que o filme Cinquenta Tons Mais Escuros seria mais fiel à obra, trazendo cenas de suspenses e de sexo mais quente.

A gravação do filme Cinquenta Tons Mais Escuros foi realizada em Vancouver - Canadá e teve início em fevereiro de 2016. Para a divulgação dos filmes, a Universal Pictures criou uma fanpage no Facebook, e nela foram postadas fotos da gravação, informações exclusivas e os vídeos que geraram grande quantidade de curtidas e comentários. As fãs conseguiram interagir com a produtora, frisando as partes da estória que elas estavam mais ansiosas para verem nos filmes.

Diante desse contexto, buscou-se conhecer um pouco da estratégia de promoção das obras do setor cinematográfico hollywoodiano, realizando uma análise a fanpage Cinquenta Tons Cinza, bem como responder a seguinte questão de pesquisa: Quais eram as expectativas das fãs da obra Cinquenta Tons, que acompanhavam as filmagens e postagens, pela fanpage oficial criada pela Universal Pictures BR, em relação ao filme Cinquenta Tons Mais Escuros?

Para a realização do estudo, o Embasamento Teórico traz a luz a contribuição mutua entre o cinema e a literatura, apresenta a trilogia Cinquenta Tons e suas repercussões e por fim retrata as Redes Sociais Virtuais - RSV. Na sequência tem-se o Método e o caminho percorrido por esse estudo empírico, que adotou a observação do universo dos fãs da obra Cinquenta Tons e, mais especificamente, dos internautas que curtiam e expressavam suas opiniões dentro da fanpage oficial Cinquenta Tons de Cinza, com ênfase no filme Cinquenta Tons Mais Escuros, sendo homens ou mulheres, que comentavam e discutiam opiniões dentro fanpage oficial da Universal Pictures BR na rede social virtual Facebook. Como Resultado obteve-se dados quantitativos e qualitativos que são articulados e discutidos com a teoria, permitindo que as Considerações Finais tragam contribuições para futuros estudos que abordem os temas: redes sociais virtuais; fanpage; obras literárias adaptadas ao cinema; trilogia Cinquenta Tons e Cinquenta Tons Mais Escuros e, também, aos empresários que desconhecem o uso das RSV como instrumento de mobilização de determinado grupo social.

\section{REFERENCIAL TEÓRICO}

\subsection{O diálogo entre o cinema e a literatura}

Desde a pré-história o homem registra os movimentos realizados. A representação artística foi uma das primeiras formas de expressão e os homens utilizavam a arte rupestre para expressar as situações 
vivenciadas no cotidiano (MAGALHÃES, 2016). Com o passar dos anos houve o aperfeiçoamento dos meios de registros utilizados, destacando-se para o contexto deste estudo: o teatro de marionetes, criado pelos chineses há aproximadamente sete mil anos atrás, o desenvolvimento da câmara escura ${ }^{5}$, por volta da metade do século XV, e a Lanterna Mágica ${ }^{6}$, criada no século XVII (FREITAS, 2015). No século XIX, com o aprimoramento da ciência óptica, o cinema se tornou realidade, na França, com o advento dos irmãos Louis e Auguste Lumiére.

Com o sucesso do cinema, abriu-se uma porta para que as obras literárias ganhassem espaço neste mercado. Chaves e Agra (2017) afirmam que não tem como precisar qual foi a primeira obra literária a ser transformada em obra cinematográfica, pois alguns apontam o clássico de 1902, "Viagem à lua", do francês George Méliès, inspirado no livro "Da Terra à Lua", como a pioneira, outros dizem que Sherlock Holmes Baffled, de 1900, baseado nas obras de Sir Arthur Conan Doyle, foi o primeiro personagem literário a ganhar as telonas dos cinemas no ano de 1903, já outros fazem referência ao pioneirismo à Alice no País das Maravilhas, lançado em 1903. Tais adaptações aconteceram há mais de um século e as obras literárias ainda continuam sendo um combustível para o cinema. Segundo Barbosa (2016), o cinema, ao longo de sua história, foi construindo e reconstruindo sua linguagem a partir de estruturas narrativas bastante específicas, bem como da relação com o tempo e o espaço, visto que isso tem de ser pensado levando-se em consideração o encadeamento de imagens.

A obra literária, quando modificada em obra cinematográfica, tem seus elementos transformados em narrativa audiovisual. O produtor do filme procura, de maneira mais realista, manter algumas características do livro original, uma vez que a adaptação cinematográfica deve expor conceitos já existentes nas obras.

Como o próprio termo indica, a adaptação fílmica constrói uma inter-relação discursiva, com um texto que posteriormente é transformado em roteiro e que, ao contrário do que muitos pensam, não se coloca de forma inferior, nem superior ao texto base, pois ele dialoga com esse texto original (RICKELI, 2015, p.1).

A ligação entre literatura e cinema, romances, contos, crônicas, poemas e novelas, inspiraram realizadores e deram origem a filmes dos mais diversos gêneros. Assim, faz-se necessário esclarecer que os filmes, de modo algum, são obrigatoriamente cópias fiéis de seus textos originais, mas sim livres adaptações que podem alterar arbitrariamente a história original, visto que se deve transformar em imagens o que está exposto no texto. A relação do cinema com a literatura vem do fato de que elas são artes que contam histórias. Ao passo que o livro proporciona aos leitores aspectos mais minuciosos da obra literária, o filme traz uma versão geral, sem muitos detalhes, deixando, muitas vezes, os leitores desapontados, pois,

estão distanciados no tempo; escritor e cineasta não têm exatamente a mesma sensibilidade e perspectiva, sendo, portanto, de esperar que adaptação dialogue não só com o texto de origem, mas com o seu próprio contexto, inclusive atualizando a pauta do livro, mesmo quando o objetivo é a identificação com os valores nele expressos (XAVIER, 2003, p.62).

\footnotetext{
${ }^{5}$ Dispositivo cúbico ou em forma de um paralelepípedo (caixa) que possui um pequeno orifício em uma de suas paredes, que são todas opacas, Criado por Leonardo da Vincci. Quando um objeto iluminado ou luminoso é colocado à frente da câmara, é formada na parede oposta ao orifício uma imagem invertida semelhante ao objeto.

${ }^{6}$ Objeto composto de um cilindro iluminado à vela, para projetar imagens desenhadas em uma lâmina de vidro, criada por Athanasius Kirchner.
} 
Nesse sentido, Xavier (2003) e Pedro (2009), salientam que a avaliação que o espectador apresenta, se referindo à fidelidade ou à falta dela em determinada adaptação, é verdadeira e deve ser levada em consideração, mas não pode ser encarada como único elemento da análise. Corroborando, Alves, De Anchieta e Frasão (2013) e Dias e Paulino (2014) apontam que as adaptações cinematográficas sempre se constituíram num grande objeto de debate para os críticos de cinema e para o público em geral.

No processo de um projeto de adaptação, o cineasta desempenha seu papel buscando, em regra, agradar ao público e aos estudiosos da área de cinema, mas, na maioria dos casos, isso não ocorre. Alterações na narrativa fílmica, que para aqueles com visão tradicionalista consideram 'traições', podem ocorrer de diversas maneiras, como por exemplo: a falta de um personagem, a adição de cenas ou de personagens, a variação de lugares ou de características de personagens. Essas mudanças, em muitos casos, levam alguns amantes da literatura a considerarem tais modificações como pontos negativos do filme, exigindo 'fidelidade' ao signatário.

Assim, o primeiro filme da obra de E. L. James, Cinquenta Tons de Cinza, sofreu várias críticas no sentido de que não teve nada de pornografia, aspecto crucial do livro, deixando a desejar na adaptação, pois as cenas mais fortes de sexo foram cortadas, sendo que as que tiveram - como a Anastásia fazendo sexo oral em Christian - duraram poucos minutos, transformando, assim, a "pornografia para mulheres" em sexo comportado (MENDES, 2015) (MORAES, 2017). Apesar das críticas, o primeiro filme da trilogia Cinquenta Tons arrecadou mais de 1,5 bilhão e foi um sucesso de bilheteria, sendo o filme da categoria R (voltado para maiores de 17 anos) mais lucrativo da história da Universal. Só no Brasil gerou pouco mais de R\$ 69 milhões (ESTADÃO, 2015).

\subsection{A história da trilogia Cinquenta Tons}

E. L. James, após ler e assistir a saga Crepúsculo teve a ideia de escrever a sua própria estória e em 2009 começou a desenvolvê-la, porém trocando o universo fictício entre lobos e vampiros, pelo universo mais real, de seres humanos com problemas psicológicos e sexuais. Aproximadamente, um ano após ao lançamento de seus primeiros livros a autora atingiu o auge da sua carreira, sendo destaque no cenário da publicação mundial, com a trilogia composta por Cinquenta Tons de Cinza, Cinquenta Tons Mais Escuros e Cinquenta Tons de Liberdade. A trilogia ficou no topo dos livros mais vendidos no mundo, se tornando best seller e batendo recordes de livros considerados consagrados, como o 'Código da Vinci' e 'Harry Potter e as Relíquias da Morte' (CARDOSO, 2013), assim Erika Leonard James entrou para a lista da Revista Times como uma das cem pessoas mais influentes do mundo (AL'HANATI, 2012). Diante de tais números, a Universal Pictures e a Focus Features compraram os direitos das obras, em 2012, por cinco milhões de dólares.

O primeiro livro, Cinquenta Tons de Cinza, adaptado para as telonas, atingiu a margem de $\mathrm{R} \$ 1,5$ bilhão em bilheteria global. A Universal Pictures anunciou que deste valor, $\mathrm{R} \$ 447$ milhões vieram dos cinemas norte-americanos, enquanto que no Brasil a obra cinematográfica, de categoria $\mathrm{R}^{7}$, rendeu um pouco mais de $\mathrm{R} \$ 69$ milhões, e o restante é a soma do acumulado do resto do mundo, se tornando o filme mais lucrativo da história da Universal Pictures (EXAME, 2016). O filme Cinquenta Tons de Cinza foi um grande sucesso, segundo o relatório anual da Ancine (2015), obtendo o maior público na semana de estreia quando comparado com os demais lançamentos do ano, comprovando que a expectativa dos fãs em relação à adaptação fílmica não foi em vão. Foram destinadas ao todo 1.087 salas para o lançamento do romance erótico, sendo uma das maiores disposições de salas do ano e alcançando, com quatro semanas de exibição, um público de 6.685.086 espectadores (ANCINE, 2015).

${ }^{7}$ Categoria R são filmes classificados para maiores de dezessete anos.

Nucleus,v.15,n.2,out.2018 
Os três filmes da trilogia Cinquenta Tons foram lançados no mês de fevereiro, no dia em que se comemora o tradicional Valentine's Day (Dia dos Namorados) nos Estados Unidos, sendo uma estratégia da Universal, pois a estória é classificada como romance e visa atrair os casais para assistem ao filme, como uma forma de comemoração do dia especial.

O segundo filme da trilogia, Cinquenta Tons Mais Escuros, teve mudanças na sua produção, um novo diretor, James Foley, e roteiros de Niall Leonard, marido da escritora, uma vez que 'Cinquenta Tons de Cinza' recebeu muitas críticas (MORAES, 2017). As gravações tiveram início em fevereiro de 2016, em Vancouver - Canadá, e depois passaram por Paris - França, com o orçamento para a adaptação cinematográfica estimado em U\$\$ 40 milhões (PORTAL 50 TONS, 2016).

Cinquenta Tons Mais Escuros causou muitas expectativas, pois é considerado pelas leitoras o melhor volume da trilogia e também porque o primeiro livro e filme tem um final inconclusivo, deixando certo suspense para o segundo livro e filme.

\subsection{Redes Sociais Virtuais - RSV}

Com o surgimento da internet houve uma revolução no meio de comunicação entre as pessoas. Recuero (2011) e Costa (2018) explicam que a chegada da internet trouxe diversas mudanças para a sociedade, entre essas mudanças, a mais significativa é a possibilidade de expressão individual e sociabilização através das ferramentas de comunicação mediada pela internet. Shimazaki e Pinto (2015) apontam que as Redes Sociais Virtuais - RSV estão relacionadas com o meio de comunicação que mais vem crescendo, tanto no mundo tecnológico, como no mundo real. As RSV constituem uma das estratégias mais utilizadas pela sociedade metropolitana, para o compartilhamento da informação e do conhecimento, mediante as relações entre os indivíduos que interagem (TOMAÉL, ALCARA, DI CHIARA, 2005).

Assim, conceitua-se que Rede Social Virtual é uma página da internet onde há interação entre pessoas, permitindo que estas criem perfis de acordo com sua personalidade, permitindo ainda que exponha suas opiniões, críticas, suas fotos, etc. Pode-se considerar RSV qualquer página que permite ao usuário construir uma imagem que o representa na internet, por meio de um perfil, como no Facebook, Blog, Linkedin, Instagram, entre outras. A interação entre participantes é feita por meio de comentários, cada um tem o livre arbítrio de opinar sobre o conteúdo disponibilizado nessas páginas e há uma exposição pública, ou seja, essa página fica disponível para todos que fazem parte da rede. As RSV permitem a formação de um elo entre as pessoas que estão conectadas, compartilhando dados, informações das mais diversificadas formas, sendo possível também a formação de comunidades virtuais e espaço para debates ou apresentação de qualquer tema que a pessoa queira expor.

Neste sentido, Costa e Picchi (2017, p. 4) apontam que:

As RSV deixaram de ser apenas um meio de conhecer pessoas com interesses semelhantes e tornaram-se também canais de divulgação e comercialização de marcas, produtos e serviços, propagação de publicidades (virais), servindo até como termômetro de vendas e receptividade, e principalmente como meio de comunicação.

O mundo está conectado através da internet, pois não existem fronteiras físicas que possa impedir essa comunicação e, assim, as RSV ampliaram a capacidade de todas as pessoas se comunicaram entre si, trazendo com mais facilidade as respostas para suas perguntas e para satisfazer suas necessidades. Shimazaki e Pinto (2015) salientam que as pessoas estão cada vez mais ligadas às RSV, tornando-a um 
fenômeno de comunicação que atinge pessoas de diferentes classes sociais, faixas etárias, graus de escolaridade e identidade culturais.

O Facebook é a RSV mais acessada pelos brasileiros e alcançou essa liderança em 2011, (IBOPE NIELSEN ONLINE, 2011), (COMSCORE, 2012). De acordo com o $6^{\circ}$ Mapa Mundial das Redes Sociais, e atingiu a marca de um 1,59 bilhão de usuários em todo o mundo (EXAME, 2016).

O Facebook disponibiliza várias ferramentas para que o seu usuário possa se expressar e mostrar os seus sentimentos, sendo as que mais se destacam: a) Feed de Notícias, onde os usuários conseguem visualizar as postagens dos seus amigos; b) Mural, onde o usuário tem a informação de todas as suas ações, conseguindo descobrir tudo o que foi curtido, comentado e compartilhado pelos seus amigos; c) Botões das reações, em forma de emoji $^{8}$, para expressar o que as pessoas estão sentindo. Em inglês essas reações recebem o nome de: 'Love', 'Haha', 'Wow', 'Sad' e 'Angry', e no Brasil passaram a ser: 'Amei', 'Haha', 'Uau', 'Triste' e 'Grr'.

Outra ferramenta que também vem se destacando, sendo utilizada frequentemente pelos usuários do Facebook, é a fanpage ou Página de Fãs, que é uma página específica dentro do Facebook direcionada para a divulgação e interação entre os usuários, geralmente utilizadas por empresas, produtos, marcas, associações, fãs clubes e ONG's. Estas fanpages estão se tornando uma ação de marketing digital eficiente e de baixo custo dentro do Facebook, pois além de os usuários poderem seguir, curtir e compartilhar informações da página e ficarem atualizados com as informações disponibilizadas, a fanpage também permite uma forma de manter uma relação próxima e amistosa entre a marca, empresa, prestação de serviço e o consumidor final, tendo um alcance de público muito maior do que em uma campanha tradicional. Uma fanpage é diferenciada do perfil normal, pois possui ferramentas específicas, como: Anúncios; Aplicativos; Quantidade de fãs ilimitadas; Lançamentos de produtos; Customização de abas. Além desses recursos, a fanpage permite que os usuários tenham uma maior interação com os seus seguidores, além de disponibilizar relatórios elaborados pelo próprio Facebook mostrando para o dono da página o que está acontecendo na sua fanpage, para que o mesmo sempre esteja em constante melhoria para seus fãs (BANDEIRA, GARCEZ, 2013).

\section{MÉTODO}

A investigação descritiva, com base na observação e analise de posts feitos na fanpage oficial da trilogia, teve como finalidade entender as expectativas dos fãs, gerada pela produção do filme Cinquenta Tons Mais Escuros.

Segundo Costa (2018, p.20) a "internet e, mais especificamente, as RSV possibilitam [...] a observação de situações, comportamentos e temas, a distribuição de diretrizes, o campo para a coleta de dados, a divulgação dos resultados e a disseminação dos conhecimentos".

Por sua vez, a observação participante tem o objetivo de colocar o pesquisador em contato direto com a realidade do tema escolhido, podendo analisar fatos e fenômenos e ter como resultado dados qualitativos, ao observar as narrativas, documentos e opiniões, quanto dados qualitativos, como explica Vianello (2013), em contrapartida a observação participante que utiliza o método de pesquisa quantitativo é objetiva (valer-se de tudo que pode quantificar), utilizando-se de números expressivos de pesquisados, sendo os dados quantificados estatisticamente.

Tendo como objeto/local de observação a fanpage oficial "Cinquenta Tons de Cinza", com o intuito de levantar informações, acompanhando as postagens e as menções que demonstram/relatam

\footnotetext{
${ }^{8}$ Emoji é uma pequena imagem que transmite a ideia de uma palavra, emoção, sentimento, utilizado em aplicativos através de mensagens eletrônicas.
} 
expectativas para próxima produção fílmica de Cinquenta Tons Mais Escuros, este método de pesquisa possibilitou o realismo da situação estudada, sem interferências de documentos e pessoas. Segundo Belei et al. (2015, p. 191), "uma observação controlada e sistemática se torna um instrumento fidedigno de investigação cientifica".

O estudo considerou seis meses, o período de janeiro de 2016 a junho de 2016, reunindo todas às notícias publicadas na fanpage oficial, tendo como foco o filme "Cinquenta Tons Mais Escuros", verificando as repercussões e a manifestação de expectativa pela obra, já que diversos fãs passaram a acompanhar a trajetória da produção da Universal e aguardavam a chegada do segundo filme, utilizando as RSV para obterem informações, e também se manifestarem, elogiando ou criticando as postagens referentes ao filme em questão. A análise foi realizada em uma única data, por isso, novos comentários, compartilhamentos e desfechos posteriores, podem ter acontecido após a data de sua observação.

Segundo Sampieri, Collado e Lucio (2014) os observadores devem registrar o que percebem seguindo regras que se aplicam invariavelmente e devem minimizar seu efeito sobre os registros e interações com os participantes observados. Gil (2008, p.112) diz que a observação é muito útil quando se deseja conhecer fatos ou situações que tenham certo caráter público, sendo "muito apropriada para o estudo das condutas mais manifestadas das pessoas na vida social".

Para a exposição das menções dos fãs, objetos das observações, houve a necessidade de recurso gráficos para preservar o anonimato dos internautas, assim as fotos foram excluídas e os nomes, tanto das fãs que fizeram a postagem como dos amigos citados, ganharam uma tarja preta. Na redação, os nomes dos internautas foram modificados por pseudônimos, garantindo total sigilo.

\section{ANÁLISE E DISCUSSÃO}

\subsection{Dados quantitativos das postagens}

Com a observação da fanpage Cinquenta Tons de Cinza e apreciação específica das postagens feitas durante o período de seis meses - de 01 de janeiro de 2016 a 31 de junho de 2016, verificou-se postagens de fotos e vídeos referentes aos três filmes da trilogia Cinquenta Tons de Cinza, sendo que Cinquenta Tons Mais Escuros e Cinquenta Tons de Liberdade na ocasião estavam em gravação, para a estreia nas telonas em 2017 e 2018, respectivamente.

As fotos publicadas na fanpage podem ser classificadas conforme os seguintes propósitos:

a) para deixar o público a par de tudo o que estava acontecendo nos bastidores das gravações de Cinquenta Tons Mais Escuros, como por exemplo, algumas cenas do filme, a revelação dos atores que participariam do elenco, cenários das gravações;

b) sobre o filme Cinquenta Tons de Liberdade;

c) que relembravam o primeiro filme da trilogia, sendo um momento saudosista;

d) algumas postagens feitas pelos próprios fãs, por exemplo, para avisar em qual canal da TV o filme Cinquenta Tons de Cinza iria ser exibido.

A análise das postagens das fotos foi realizada em 15/10/2016, sendo assim, a quantidade de curtidas, comentários e compartilhamentos pode sofrer alterações em nova análise. O levantamento de dados quantitativos permitiu a construção da tabela 1 : 
Tabela 1 - Postagens de fotos

\begin{tabular}{cccccc}
\hline \multicolumn{7}{c}{ Fanpage: Cinquenta Tons de Cinza } \\
\hline Mês & Gênero & Quantidade & Curtidas & Comentários & Compartilhamento \\
\hline $\mathbf{0 1 / 2 0 1 6}$ & Foto & 98 & 144.329 & 4.737 & 3.727 \\
\hline $\mathbf{0 2 / 2 0 1 6}$ & Foto & 123 & 274.485 & 11.961 & 6.925 \\
\hline $\mathbf{0 3 / 2 0 1 6}$ & Foto & 151 & 437.091 & 9.553 & 8.294 \\
\hline $\mathbf{0 4 / 2 0 1 6}$ & Foto & 68 & 194.466 & 4.486 & 4.258 \\
\hline $\mathbf{0 5 / 2 0 1 6}$ & Foto & 63 & 285.446 & 7.592 & 12.543 \\
\hline $\mathbf{0 6} / \mathbf{2 0 1 6}$ & Foto & 98 & 313.755 & 5.212 & 9.286 \\
\hline
\end{tabular}

No mês de janeiro 2016, a publicação 9 que mais obteve repercussão foi postada no dia 28/01/2016 (quinta-feira, às 20h44), contendo 7.700 curtidas, 417 comentários e 188 compartilhamentos. Essa publicação revelava a atriz Elena Lincoln que interpreta a Mrs. Robinson no filme.

Figura 1 Comentários de fãs sobre aprovação da atriz

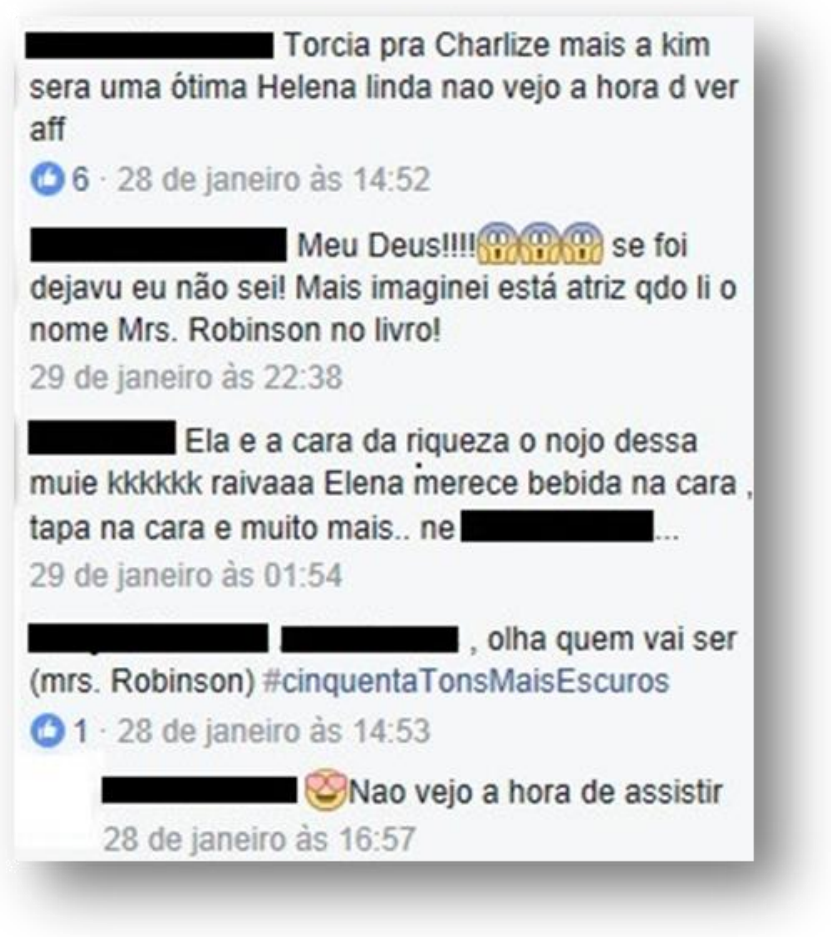

Fonte: Facebook (2016)

Em fevereiro de 2016, a publicação ${ }^{10}$ que mais obteve repercussão foi postada no dia 20/02/2016, com 12.000 curtidas, 1.300 comentários e 437 compartilhamentos. Essa publicação apresenta o ator Brant Daugherty, que interpreta Luke Sawyer, um dos seguranças de Christian Grey.

\footnotetext{
${ }^{9}<$ https://www.Facebook.com/cinquentatonsdecinza/photos/a.278824078885362.50278.261616750606095/73204071 $0230361 /$ type $=3 \&$ theater $>$.

${ }^{10} \mathrm{https} / / /$ www.Facebook.com/cinquentatonsdecinza/photos/a.278824078885362.50278.261616750606095/74206855 5894243/?type=3\&theater $>$. Acesso em: 20. out. 2016.
} 
Figura 2 - Comentários sobre a aprovação do ator

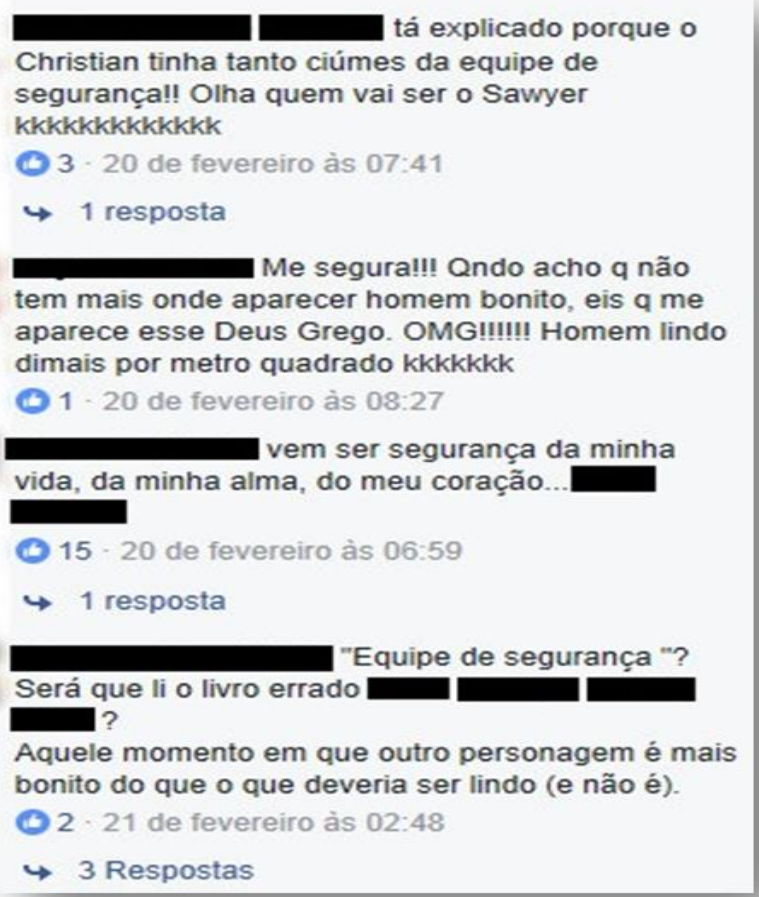

Fonte: Facebook (2016)

No mês de março de 2016, a foto ${ }^{11}$ com maior repercussão foi postada em 06/03/2016, contendo 13.000 curtidas, 302 comentários e 355 compartilhamentos. Essa publicação é a foto do ator Jamie Dordan, que interpreta Christian Grey na trilogia.

Figura 3 - Comentários de fãs sobre aprovação do personagem Grey.

caramba eh esse homem eh um gato,mesmo...tomara que esse filme cheguei logo..tomara que não demori muito porque eu já estou imaginado como vai ser, filme cinquenta tons mais escuros M $_{\text {kkkkk }}$

7 de março às 17:04

Não vejo a hora, mas esperar tb é , bom, as noticias, as fotos aumentam a ansiedade. porém é legal demais acompanhar o que for possivel, tudo no filme é bom, até a espera.

(1) 4. 6 de março às 17:06

Já estou morrendo com as fotos das gravações de 50 tons mais escuros, imagina no cinema assistindo em 2017, vou pirar!!

(1) 1 - 6 de março às 19:15

Aff num sei pra quê tanta demora para o lançamento de cinquenta tons mais escuros só pra gente ficar anciosa!!!!! Nam

(1) 1 - 6 de março às 17:07

Fonte: Facebook (2016)

\footnotetext{
${ }^{11}$ https://www.Facebook.com/cinquentatonsdecinza/photos/a.278824078885362.50278.261616750606095/74860235 $8574196 /$ ?type $=3 \&$ theater $>$.
} 
Em abril de 2016, a publicação ${ }^{12}$ que mais repercutiu foi postada em 07/04/2016, contendo 11.000 curtidas, 7.592 comentários e 12.543 compartilhamentos. Essa publicação é a foto de Jamie Dordan no set de gravação de Cinquenta Tons Mais Escuros.

Figura 4 - Comentários de aprovação do personagem Grey

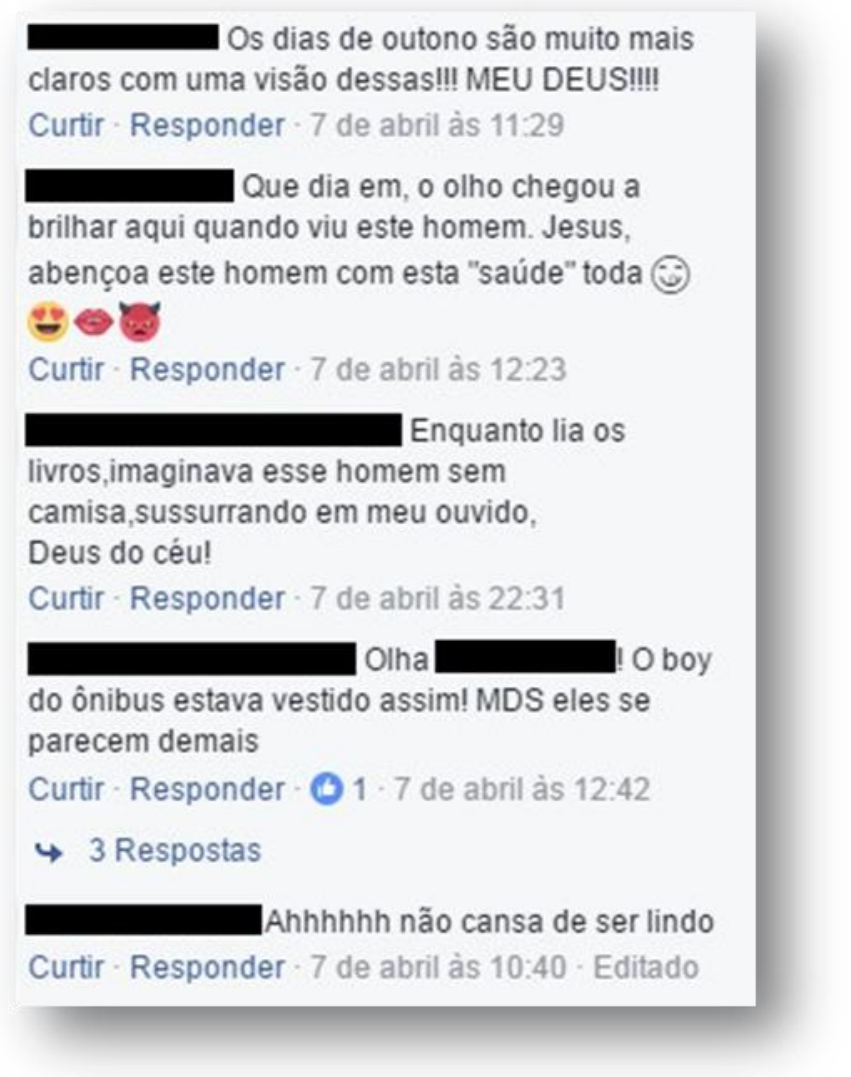

Fonte: Facebook (2016).

Em maio de 2016, a publicação ${ }^{13}$ do dia 13/05/2016 obteve maior repercussão, com 48.000 curtidas, 2.600 comentários e 5.358 compartilhamentos. Essa publicação é a foto da Jamie Dordan (Christian Grey) e Dakota Jhonson (Anastásia Steele) de noivos, relacionado com um trecho do livro Cinquenta Tons de Liberdade, $3^{\circ}$ filme.

Já no mês de junho de 2016, a foto ${ }^{14}$ postada em 25/06/2016, a foto que mais obteve repercussão no mês teve 11.000 curtidas, 412 comentários e 310 compartilhamentos. Essa publicação é de uma cena de Christian Grey no quarto vermelho da dor, em Cinquenta Tons de Cinza.

\footnotetext{
${ }^{12} \mathrm{https} / / / \mathrm{www}$. Facebook.com/cinquentatonsdecinza/photos/a.278824078885362.50278.261616750606095/76704395 3396703/?type=3\&theater

${ }^{13}$ https://www.Facebook.com/cinquentatonsdecinza/photos/a.278824078885362.50278.261616750606095/78579552 $1521546 /$ ?type $=3 \&$ theater

${ }^{14}$ https://www.Facebook.com/cinquentatonsdecinza/photos/a.278824078885362.50278.261616750606095/80716646 9384451/?type $=3 \&$ theater
}

Nucleus,v.15,n.2,out.2018 
Figura 5 - Comentários sobre Grey

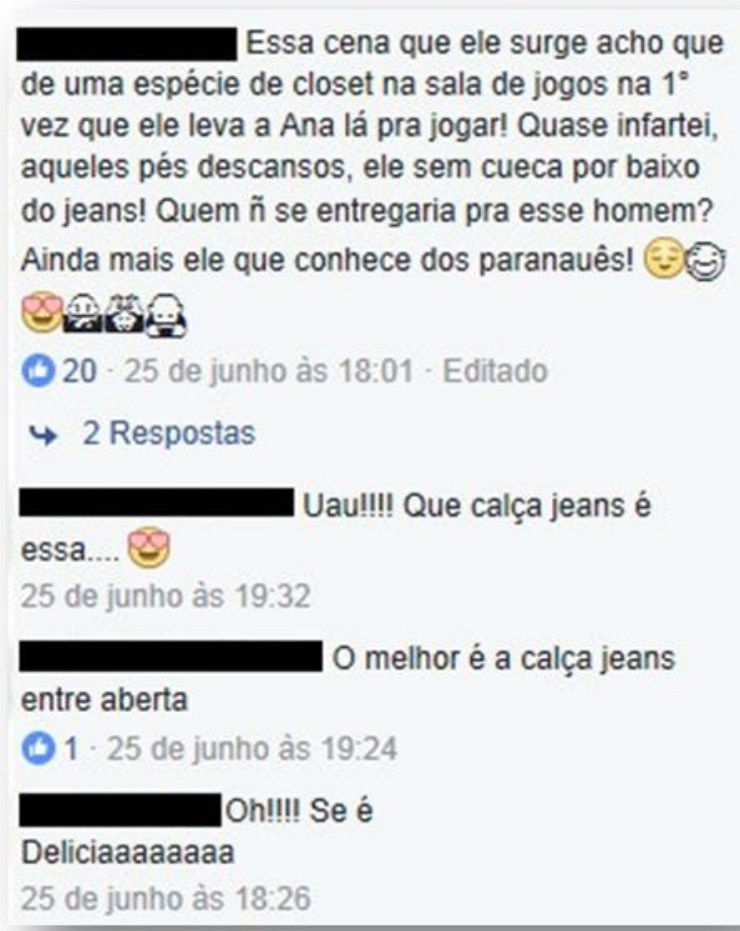

Fonte: Facebook (2016).

No período analisado, foram postadas 601 fotos, gerando, assim, 1.649 .572 curtidas, 43.451 comentários e 45.033 compartilhamentos. Ou seja, uma média de 2.750 curtidas, 73 comentários e 75 compartilhamentos por foto. Um ponto a ser discutido na pesquisa é que as 4 fotos mais curtidas dentro do período, $1^{\circ}$ semestre de 2016 , foram publicadas após às $12 \mathrm{~h} 00$, dando indícios que a maioria dos seguidores da fanpage acessavam a página no período da tarde.

Assim como as fotos, os vídeos postados na fanpage geraram repercussão dentro da página. Os vídeos publicados apresentam pequenas cenas que irão compor o filme e deixaram os fãs 'enlouquecidos' e ansiosos para a estreia em 2017, como ficam evidenciados nos comentários de cada postagem. Muitos destes vídeos são editados e publicados pelos próprios fãs, colocando suas músicas favoritas e/ou as que eles julgam ser apropriadas para as cenas. O levantamento de dados quantitativos permitiu a construção da tabela 2, a seguir:

Tabela 2 - Postagens de vídeos

(Continua)

Fanpage: Cinquenta Tons de Cinza

\begin{tabular}{cccccc}
\hline Data & Gênero & Curtidas & Comentários & Compartilhamento & Visualizações \\
\hline $\mathbf{0 9 / 0 1 / 2 0 1 6}$ & Vídeo & 5.313 & 505 & 1281 & 93.000 \\
\hline $\mathbf{1 1 / 0 1 / 2 0 1 6}$ & Vídeo & 1.800 & 169 & 247 & 25.000 \\
\hline $\mathbf{1 2 / 0 1 / 2 0 1 6}$ & Vídeo & 7.800 & 1.300 & 1.631 & 123.000 \\
\hline $\mathbf{1 3 / 0 1 / 2 0 1 6}$ & Vídeo & 2.400 & 109 & 81 & 41.000 \\
\hline $\mathbf{1 4 / 0 1 / 2 0 1 6}$ & Vídeo & 2.600 & 75 & 248 & 2.600 \\
\hline $\mathbf{1 9 / 0 1 / 2 0 1 6}$ & Vídeo & 3.900 & 292 & 655 & 47.000 \\
\hline $\mathbf{2 0 / 0 1 / 2 0 1 6}$ & Vídeo & 4.200 & 290 & 1.137 & 62.000 \\
\hline $\mathbf{2 2 / 0 1 / 2 0 1 6}$ & Vídeo & 3.400 & 164 & 604 & 45.000 \\
\hline
\end{tabular}


Tabela 2 - Postagens de vídeos

(Continua)

Fanpage: Cinquenta Tons de Cinza

\begin{tabular}{|c|c|c|c|c|c|}
\hline Data & Gênero & Curtidas & Comentários & Compartilhamento & Visualizações \\
\hline $3 / 01 / 2016$ & Vídeo & 2.500 & 76 & 137 & 34.000 \\
\hline 31/01/2016 & Vídeo & 2.500 & 42 & 130 & 20.000 \\
\hline $06 / 02 / 2016$ & Vídeo & 2.700 & 173 & 323 & 34.000 \\
\hline 09/02/2016 & Vídeo & 3.200 & 189 & 374 & 38.000 \\
\hline $10 / 02 / 2016$ & Vídeo & 1.600 & 41 & 41 & 23.000 \\
\hline $10 / 02 / 2016$ & Vídeo & 5.800 & 686 & 883 & 82.000 \\
\hline 13/02/2016 & Vídeo & 1.900 & 50 & 103 & 21.000 \\
\hline 18/02/2016 & Vídeo & 1.200 & 60 & 188 & 19.000 \\
\hline 23/02/2016 & Vídeo & 2.400 & 123 & 148 & 22.000 \\
\hline 23/02/2016 & Vídeo & 2.200 & 74 & 92 & 26.000 \\
\hline 24/02/2016 & Vídeo & 4.400 & 445 & 667 & 58.000 \\
\hline 27/02/2016 & Vídeo & 2.600 & 47 & 95 & 21.000 \\
\hline 29/02/2016 & Vídeo & 2.100 & 75 & 74 & 20.000 \\
\hline $01 / 03 / 2016$ & Vídeo & 1.500 & 33 & 25 & 14.000 \\
\hline $02 / 03 / 2016$ & Vídeo & 1.300 & 27 & 24 & 15.000 \\
\hline 03/03/2016 & Vídeo & 2.300 & 28 & 102 & 21.000 \\
\hline $05 / 03 / 2016$ & Vídeo & 1.200 & 34 & 33 & 20.000 \\
\hline 07/03/2016 & Vídeo & 1.100 & 31 & 31 & 24.000 \\
\hline $10 / 03 / 2016$ & Vídeo & 1.800 & 51 & 72 & 20.000 \\
\hline $12 / 03 / 2016$ & Vídeo & 1.300 & 22 & 23 & 14.000 \\
\hline $14 / 03 / 2016$ & Vídeo & 2.000 & 59 & 93 & 23.000 \\
\hline $20 / 03 / 2016$ & Vídeo & 2.000 & 63 & 76 & 21.000 \\
\hline 23/03/2016 & Vídeo & 2.500 & 54 & 145 & 21.000 \\
\hline $25 / 03 / 2016$ & Vídeo & 440 & 6 & 3 & 9.200 \\
\hline $25 / 03 / 2016$ & Vídeo & 733 & 9 & 12 & 9.300 \\
\hline $25 / 03 / 2016$ & Vídeo & 718 & 7 & 6 & 14.000 \\
\hline $31 / 03 / 2016$ & Vídeo & 2.100 & 76 & 95 & 24.000 \\
\hline $02 / 04 / 2016$ & Vídeo & 2.500 & 113 & 111 & 34.000 \\
\hline $04 / 04 / 2016$ & Vídeo & 1.300 & 35 & 36 & 20.000 \\
\hline $04 / 04 / 2016$ & Vídeo & 1.700 & 100 & 60 & 22.000 \\
\hline $15 / 04 / 2016$ & Vídeo & 2.000 & 48 & 94 & 21.000 \\
\hline $16 / 04 / 2016$ & Vídeo & 3.200 & 210 & 528 & 35.000 \\
\hline $16 / 04 / 2016$ & Vídeo & 5.200 & 254 & 306 & 92.000 \\
\hline $22 / 04 / 2016$ & Vídeo & 1.900 & 51 & 91 & 15.000 \\
\hline $25 / 04 / 2016$ & Vídeo & 1.600 & 25 & 59 & 10.000 \\
\hline $07 / 05 / 2016$ & Vídeo & 2.400 & 35 & 125 & 19.000 \\
\hline $09 / 05 / 2016$ & Vídeo & 2.200 & 82 & 95 & 20.000 \\
\hline $12 / 05 / 2016$ & Vídeo & 526 & 1 & 12 & 6.800 \\
\hline $12 / 05 / 2016$ & Vídeo & 847 & 14 & 16 & 11.000 \\
\hline $13 / 05 / 2016$ & Vídeo & 1.300 & 38 & 29 & 10.000 \\
\hline
\end{tabular}


Tabela 2 - Postagens de vídeos

(Conclusão)

\begin{tabular}{|c|c|c|c|c|c|}
\hline \multicolumn{6}{|c|}{ Fanpage: Cinquenta Tons de Cinza } \\
\hline Data & Gênero & Curtidas & Comentários & Compartilhamento & Visualizações \\
\hline 6/05/2016 & Vídeo & 2.900 & 107 & 158 & 23.000 \\
\hline $17 / 05 / 2016$ & Vídeo & 5.500 & 972 & 318 & 62.000 \\
\hline $19 / 05 / 2016$ & Vídeo & 822 & 11 & 18 & 12.000 \\
\hline $19 / 05 / 2016$ & Vídeo & 6.900 & 655 & 1.455 & 109.000 \\
\hline $22 / 05 / 2016$ & Vídeo & 3.100 & 32 & 125 & 26.000 \\
\hline $23 / 05 / 2016$ & Vídeo & 3.000 & 89 & 82 & 21.000 \\
\hline $26 / 05 / 2016$ & Vídeo & 3.000 & 55 & 129 & 30.000 \\
\hline $27 / 05 / 2016$ & Vídeo & 2.300 & 24 & 43 & 20.000 \\
\hline $28 / 05 / 2016$ & Vídeo & 1.500 & 14 & 22 & 20.000 \\
\hline $28 / 05 / 2016$ & Vídeo & 3.200 & 45 & 110 & 28.000 \\
\hline 29/05/2016 & Vídeo & 7.100 & 191 & 494 & 51.000 \\
\hline $30 / 05 / 2016$ & Vídeo & 4.500 & 86 & 159 & 28.000 \\
\hline $05 / 06 / 2016$ & Vídeo & 3.300 & 73 & 122 & 40.000 \\
\hline $10 / 06 / 2016$ & Vídeo & 3.000 & 122 & 102 & 27.000 \\
\hline $12 / 06 / 2016$ & Vídeo & 6.700 & 84 & 266 & 45.000 \\
\hline $14 / 06 / 2016$ & Vídeo & 3.200 & 226 & 173 & 29.000 \\
\hline $19 / 06 / 2016$ & Vídeo & 2.600 & 78 & 120 & 23.000 \\
\hline $20 / 06 / 2016$ & Vídeo & 1.600 & 17 & 23 & 15.000 \\
\hline 21/06/2016 & Vídeo & 3.600 & 59 & 96 & 25.000 \\
\hline $25 / 06 / 2016$ & Vídeo & 1.100 & 15 & 14 & 9.000 \\
\hline
\end{tabular}

Fonte: Elaboração própria através de dados obtidos na fanpage cinquenta tons.

Dentro do período de janeiro a junho de 2016, a fanpage teve 68 vídeos publicados, totalizando 183.099 curtidas, 9.446 comentários, 15.470 compartilhamentos e 2.064 .90 visualizações. Em média, são 2.693,00 curtidas, 139 comentários, 227 compartilhamentos e 2.693 visualizações por vídeo publicado. O vídeo que mais obteve repercussão foi publicado em 12/01/2016, sendo a publicação mais curtida com 7.800, comentada por 1.300 , compartilhada por 1.631 e visualizada 123.000 vezes. Com 29 segundos, o vídeo é uma prévia do trailer de Cinquenta Tons Mais Escuros, o que demonstra a euforia dos fãs com o lançamento do segundo filme da trilogia.

Através da análise no perfil de alguns fãs, foi possível verificar que a maioria são jovens adultas, algumas solteiras e outras casadas; há mães e grávidas, que interagem com a fanpage, curtindo, comentando e visualizando as postagens. Esse estudo não se propôs a descrever o perfil dos fãs da obra, mas a observação de alguns perfis possibilitou conhecer o público alvo que participava da fanpage. Assim, fica como sugestão para futuros estudos o conhecimento do perfil dos leitores, dos telespectadores e dos fãs, tanto dos livros quanto dos filmes, e, ainda, o perfil dos adeptos de cada fanpage que aborda a trilogia.

\subsection{Comentários nos Posts da fanpage}

Após a observação sistêmica dos comentários realizados, no período de 01 de janeiro de 2016 a 31 de junho de 2016, nas publicações na fanpage oficial Cinquenta Tons de Cinza, foi possível constatar que: 
a) os principais comentários nos posts demonstravam ansiedade para o lançamento do filme Cinquenta Tons Mais Escuros no cinema. Havia expectativa e prévio julgamento de que o segundo seria melhor que o primeiro filme;

b) os leitores, maioria do sexo feminino, almejavam ver o segundo filme da trilogia e faziam convites para ir ao cinema com amigas, irmãs, primas, namorados, maridos, etc. O público esperado para ir ao cinema era o mesmo que assistiu ao primeiro filme, que queriam ver a continuação da trilogia, porém, existiam, em menor quantidade, aqueles que ainda não havia assistido ao primeiro filme, mas estavam curiosos por ser um assunto muito comentado nas RSV;

c) o público declarava que o segundo filme da trilogia estava demorando muito para ser lançado no cinema, dois anos após o primeiro. Os fãs estavam contando os dias para poder ver o casal Anastásia e Christian nas telonas, já que o segundo livro é o considerado o "queridinho" deles;

d) a principal motivação dos leitores para irem ao cinema estava atrelada ao fato do encantamento pela estória e o lado romântico de Christian Grey, acreditando que o amor pode superar qualquer coisa.

Em relação ao elenco do filme, percebeu-se que, de modo geral, os fãs aprovaram os atores que participaram de Cinquenta Tons Mais Escuros. A respeito, registra-se:

a) Eric Johnson interpretando Jacky Hyde, o maníaco que ataca Anastásia Steele. Teve aprovação da maioria dos fãs, porém houveram alguns comentários de desagrado em relação ao autor com o personagem do livro.

Internauta SPCS: "no livro, Ana o descreve como: jovem de cabelo vermelho, amarrado e um rabo de cavalo... Algo terá que ser feito no cabelo de Eric Johnson" (12/02/2016, 17h40), e a seguidora Internauta LASO rebate: "Adorei. A cara dele combina perfeitamente com o que eu imaginava... lógico, alguns detalhes terão que ser vistos como o cabelo comprido né. Mas nada que um aplique e algumas mudanças não resolva... Kkk Acabou a ansiedade. Ai meu Deus. Chega logo 2017 (12/02/2016, 18h26);

b) Elena Lincoln ficou encarregada de interpretar a personagem Mrs. Robinson. A análise dos comentários evidencia que ela é umas das personagens mais odiadas da saga, por conta de fazer Christian Grey como seu submisso e por tentar interferir no relacionamento entre Grey e Anastásia. A revelação da sua personagem gerou muita reverberação na fanpage, como ficou constatado na tabela de fotos, sendo uma das fotos que mais recebeu curtidas, comentários e compartilhamentos.

Internauta VSSO: "Amiga Internauta KMSO até que enfim! Agora já temos alguém para odiar hahahahahaha" (28/01/2016, 21:14), outra seguidora, Internaura EBSO, completa "A demônia da Elena vai ser linda hein!!!" (28/01/2016, 20:47);

c) Bella Heathcote ficou responsável pelo papel de Leila que foi uma das submissas do Sr. Grey e a 'louca' que persegue o casal. Na primeira foto que foi postada na fanpage (05/02/2016), houve julgamento de que a atriz era parecida com o que as pessoas imaginavam para o papel de Leila, porém ela não tinha os olhos azuis da atriz. 
Internauta TSSO "Ué, a Leila tem olhos castanhos! Mas de qualquer jeito, vão ter que transformar ela de uma princesa em uma doida varrida!!! Estou louca para ver o resultado" (05/02/2016, 18:11).

Na postagem do dia 02/03/2016 aparece Bella com o cabelo pintado de escuro, e com lentes de contato na cor castanho, tal postagem entusiasmou os fãs, como constatado nos comentários da foto.

Internauta JFSO "Tive um ataque quando escolheram a atriz, mas agora vejo que escolheram muito bem, ela não está mais bonita! Que cara de louca..." (02/03/2016), e Internauta VXM complementa "E tinha muita gente reclamando da atriz que era loira e de cabelo curto o povo não tem paciência, ta perfeita amei!" (02/03/2016, 16:19);

d) para interpretar Luke Sawyer, um membro da equipe de segurança do Sr. Grey, foi escolhido o ator Brant Daugherty, e essa divulgação teve a aprovação de imediato dos fãs que seguem a fanpage oficial, pois a foto do ator está no ranking das mais curtidas, comentadas e compartilhadas no mês de fevereiro. Algumas fãs acham que esse ator é tão lindo que chega a ser mais interessante que Jamie Dordan, que interpreta o Sr. Grey.

Internauta EMSO "Sinceramente, colocar um cara mais bonito e novo que o Christian parece que quer mudar a história e colocar a Ana como pistoleira (...)" (20/02/2016, 21:12).

Internauta RASO "Acho que ele está mais pra Grey, não que eu ache o Jamie Dordan feio ele é bonito, mas para ser o Christian Grey tem que ser mega hiper lindo como ela descreve no livro." (20/02/2016).

A Universal Pictures também utilizou como estrátegia de marketing ações que geravam e/ou ampliavam as expectativas. Foram criadas várias páginas dentro das RSV, como a fanpage analisada por esse estudo, para que os fãs acompanhassem os batisdores do filme, conheçem os personagens e os cenarios, fomentando assim o lançamento do filme. Segundo Santos (2004) e Bittencourt (2011) as estratégias de marketing do setor, visam instigar a curiosidade do público e promover expectativa, sem apresentar muito sobre a obra cinematográfica, para alimetar comentários e rumores ao longo dos meses que antecedem o lançamento. Assim, quando o filme foi lançado no cinema os fãs foram assistir mesmo não tendo certeza da qualidade da produção, mas possuiam as expectativas geradas por tais ações. Com a ida desses fãs ao cinema, consequentemente há boa bilheteria e isso é reverberado nas mídias, o que remete a novos telespectadores.

Os dados analisados salientam que a fanpage oficial gerou grande expectativa, pois o trailer que foi postado no dia 13 de setembro de 2016 obteve, até a data do dia 23/10/2016, a quantidade de 2.200 visualizações, 37.000 curtidas, 16.198 comentários e 36.107 compartilhamentos. Segundo Rollingstone (2016), o trailer bateu um recorde, com mais de 115 milhões de visualizações no YouTube, Facebook e Instagram, em 24 horas, ultrapassando o trailer de "Star Wars: o despertar da força", recordista em 2015.

\section{CONSIDERAÇÕES FINAIS}

A trilogia Cinquenta Tons foi um assunto muito repercutido pelas mídias sociais desde o seu lançamento no mercado literário. A primeira obra literária que foi adaptada para o cinema, Cinquenta Tons de Cinza, teve várias críticas por não seguir fielmente o livro, porém, isso não atrapalhou o sucesso do filme, gerando expectativa dos fãs para as próximas produções fílmicas dos demais livros. 
O presente estudo buscou conhecer e responder quais eram as expectativas das fãs da obra Cinquenta Tons, que acompanhavam as filmagens e postagens, pela fanpage oficial criada pela Universal Pictures BR, em relação ao filme Cinquenta Tons Mais Escuros, verificando, com base na observação e análise dos comentários feitos na respectiva fanpage, que os fãs gostaram do elenco escolhido para o filme e aguardavam ansiosamente sua estreia nas telonas.

Conclui-se, também, que a estratégia de marketing de gerar expectativa durante a produção do filme faz com que os fãs fiquem ansiosos para irem ao cinema logo na estreia, uma vez que já acompanharam todo o processo de seu desenvolvimento, estimulando a curiosidade e promovendo euforia para conhecer o resultado final. Com essa ação, pressupõe-se que o filme atingiria um número expressivo de vendas de bilheterias logo na primeira semana, gerando repercussão nas mídias sociais e, consequentemente, ampliando ainda mais o público até o final de sua exibição, garantindo o sucesso almejado pela produtora.

\section{REFERÊNCIAS}

ANCINE - Agência Nacional do Cinema. Anuário Estatístico do Cinema Brasileiro 2015. OCA Observatório Brasileiro do Cinema e do Audiovisual, 2015.

AL'HANATI, Yuri. Enfim, um best seller erótico. Cardeno G, Literatura, publicado em: 11/08/2012. Gazeta do Povo. Disponível em: https://www.gazetadopovo.com.br/caderno-g/enfim-um-best-sellererotico-1ryfpt93o7ijqg8sab39p6csu. Acesso em: 18 jun. 2018.

ALVES, S. F.; DE ANCHIETA, A.M. LL; FRASÃO, M. C. Interfaces, ressignificações e crítica da adaptação da literatura para o cinema. Tradterm, v. 21, p. 97-129, 2013.

BANDEIRA, M. O. R., GARCEZ, R. de O. Como comunicar o cliente através do Facebook: O caso da fanpage da Trifil. In: CONGRESSO DE CIÊNCIAS DA COMUNICAÇÃO NA REGIÃO SUL, 14. Anais...- S. Cruz do Sul - RS - 0/05 a 01/06/2013.

BARBOSA, A. R. de F. A narrativa como ensaio para aprendizagem da História: arte e ficção na constituição do tempo e de si. 2016. 169 f. Dissertação (Mestrado em História Social) - Universidade Estadual do Rio de Janeiro, Centro de Didática da História e Ensino de História, Escola de História, Rio de Janeiro.

BELEI, R.A. et al. O uso de entrevista, observação e videogravação em pesquisa qualitativa. Cadernos de educação, FaE/PPGE/UFPel, n. 30, jan/jun.2008. p.187-199.

BITTENCOURT, G.H.F. Estratégias Publicitárias Cinematográficas: a influência dos cartazes. In: Sociedade Brasileira de Estudos Interdisciplinares da Comunicação In: CONGRESSO BRASILEIRO DE CIÊNCIAS DA COMUNICAÇÃO NA REGIÃO NORDESTE,13. 2011, Maceió. Anais... Maceió: Intercom, 2011. p. 1 - 15.

CARDOSO, T. C. A. Quando a produção e a recepção se entrelaçam: Um estudo de caso do fenômeno literário Cinquenta Tons de Cinza. 2013. 84 f. Monografia (Graduação) - Curso de Relações Publica Comunicação Social, Universidade Federal do Rio Grande do Sul, Porto Alegre.

CHAVES, D. M. B. de M.; AGRA, A. R. M.C. e C. Traços árcades no cinema: uma análise do filme Into The Wild. In: CONGRESSO DE CIÊNCIAS DA COMUNICAÇÃO NA REGIÃO NORDESTE, 19. Anais... 29 de junho a 1 de julho de 2017. Fortalece/CE, Brasil, 2017. p.01-12. 
COMSCORE. Facebook Blasts into Top Position in Brazilian Social Networking Market Following Year of Tremendous Growth. Insights, Press Releases, 17/01/2012. Disponível em:

<http://www.comscore.com/Insights/Press_Releases/2012/1/Facebook_Blasts_into_Top_Position_in_Brazilian_Soc ial_Networking_Market .Acesso em: 06 jun. 2018.

COSTA, B.R. L.. Bola de Neve Virtual: O Uso das Redes Sociais Virtuais no Processo de Coleta de Dados de uma Pesquisa Científica. Revista Interdisciplinar de Gestão Social, v. 7, n. 1, 2018.

COSTA, B.R. L.; PICCHI, D. As relações entre os consumidores do século 21 e as empresas, no âmbito da internet, pelas redes sociais virtuais. Revista da FAE, Curitiba, v. 20, n.1, p.7-26, jan./jun. 2017.

DIAS, D.L. F.; PAULINO, J. K. J. Cinema e literatura: artes em diálogo. Revista Colineares, v. 2, n. 1, Jul/Dez, 2014, p. 109-133. Programa de Pós-Graduação em Ciência da Linguagem - UERN, 2014.

ESTADÃO, O Estado de São Paulo. Cinquenta Tons de Cinza arrecada mais de R\$ 1,5 bilhão em bilheteria. Publicado em: 06 mar. 2015. Disponível em: <

https://cultura.estadao.com.br/noticias/cinema,cinquenta-tons-de-cinza-arrecada-mais-de-r-1-5-bilhao-embilheteria, 1645757 > . Acesso em: 12 jun. 2018.

EXAME, Revista. 50 tons de Cinza arrecada mais de R\$1,5 bilhão em bilheteria. Publicado em: 06 mar. 2016. Disponível em: https://exame.abril.com.br/estilo-de-vida/50-tons-de-cinza-arrecada-mais-de-r-1-5-bilhaoem-bilheteria/ . Acesso em: 18 jun. 2018.

EXAME, Revista. Facebook mantém liderança no mapa mundial das redes sociais. Publicado em: 22/02/2016. Disponível em:

http://exame.abril.com.br/tecnologia/noticias/Facebook-mantem-lideranca-no-mapa-mundial-das-redessociais . Acesso em: 19 jun. 2018.

FREITAS,_A.C.B. Uma relação entre arquitetura e cinema. 2015. 106f. DISSERTAÇÃO (Mestrado) Mestrado Integrado em Arquitetura, Faculdade de Arquitetura e Artes da Universidade Lusíada de Lisboa, Lisboa, Portugal, 2015.

GIL, A. C. Métodos e técnicas de pesquisa social. 6.ed. São Paulo: Atlas, 2008.

IBOPE NIELSEN ONLINE. Total de pessoas com acesso à internet atinge 77,8 milhões. Publicado em: 09/09/2011 Disponível em: http://www.ibope.com.br/ptbr/noticias/Paginas/Total\%20de\%20pessoas\%20com\%20acesso\%20\%C3\%A0\%20internet $\% 20$ atinge $\% 20$ 77,8\%20milh\%C3\%B5es.aspx . Acesso em 08 jun. 2018.

MAGALHÃES, S. M. C. A arte rupestre no centro-norte do Piauí: indícios de narrativas icônicas. 2011. 457f. (Tese de Doutorado) Doutorado em História - Universidade Federal Fluminense. Niterói, 2011.

MENDES, L. G1 já viu: '50 tons de cinza' perde a graça ao mostrar sexo comportado. Publicado em: 11/02/2015. Disponível em: http://g1.globo.com/pop-arte/cinema/noticia/2015/02/g1-ja-viu-50-tons-decinza-perde-graca-ao-mostrar-sexo-comportado.html . Acesso em: 12 jun. 2018.

MORAES, F. "Cinquenta Tons Mais Escuros": o que muda na franquia erótica. Metrópoles. Publicado em: 08/02/2017. Disponível em: https://www.metropoles.com/entretenimento/cinema/cinquenta-tonsmais-escuros-o-que-muda-na-franquia-erotica. Acesso em: 19 jun. 2018.

O GLOBO. '50 tons de cinza' ultrapassa a marca de 100 milhões de cópias vendidas. Publicado em:

26/02/2014. Disponível em: https://oglobo.globo.com/cultura/50-tons-de-cinza-ultrapassa-marca-de-100milhoes-de-copias-vendidas-11727715\#ixzz5ItBO8vxd. Acesso em: 19 jun. 2018. 
PEDRO, E.de S. Estratégias narrativas em O tambor: o diálogo entre a literatura e o cinema. 2009. 137f. Dissertação (Mestrado em Língua e Literatura Alemã) - Faculdade de Filosofia, Letras e Ciências Humanas, Universidade de São Paulo. São Paulo, 2009.

PORTAL 50 TONS. Pré-produção de Cinquenta Tons Mais Escuros. Disponível em: http://portal50tons.com.br/category/universal-pictures/ . Acesso em: 15 fev. 2016.

RECUERO, R. Redes Sociais na Internet. 2. ed. Porto Alegre: Sulina, 2011.

ROLLINGSTONE. Trailer de Cinquenta Tons Mais Escuros supera o de Star Wars em visualizações. Publicado em: 16/09/2016. Disponível em: http://rollingstone.uol.com.br/noticia/trailer-deicinquenta-tons-mais-escurosi-supera-istar-warsi-em-visualizacoes/. Acesso em: 22 jun. 2018.

RICKELI, A.D. Cinema e Literatura: a adaptação em cena. Anais do XXXVIII Congresso Brasileiro de Ciências da Comunicação, Rio de Janeiro, 4 a 7/9/2015. Disponível em:

http://portalintercom.org.br/anais/nacional2015/resumos/R10-3574-1.pdf .Acesso em: 12 jun. 2018.

SAMPIERI, R. H.; COLLADO, C. F.; LUCIO, P. B. Metodología de la investigación. $6^{\text {a }}$ edição, México: McGraw-Hill, 2014.

SANTOS, C. M. N.dos. Trailer: Cinema e publicidade no mesmo rolo. Um estudo do trailer e o movie marketing ilustrado pela campanha de lançamento do filme Cidade de Deus. 2004. F. Dissertação (Mestrado em Comunicação) Universidade Federal Fluminense.

SHIMAZAKI, V.K.; PINTO, M.M.M.P. A influência das redes sociais na vida dos seres humanos. Fasci-Tech - Periódico Eletrônico da FATEC-São Caetano do Sul, São Caetano do Sul, v. 1, n. 5, Out/Dez 2011, p. 171-179.

TOMAÉL, M.I.; ALCARA, A.R.; DI CHIARA, I.G. Das Redes Sociais à inovação. Ci. Inf., Brasília, v. 34, n. 2, p. 93-104, maio/ago. 2005. Disponível em: < http://www.scielo.br/pdf/ci/v34n2/28559.pdf/> . Acesso em: 19 jun. 2018.

VIANELLO, L. P. Métodos e técnicas de pesquisa. EAD-Educação à Distância. 2013. Disponível em: http://disciplinas.nucleoead.com.br/pdf/Livro mtp.pdf . Acesso em: 19 jun. 2018.

XAVIER, I. Do texto ao filme: a trama, a cena e a construção do olhar no cinema. In. PELLEGRINI, Tânia et al. Literatura, Cinema e Televisão. São Paulo, Editora Senac São Paulo. Instituto Itaú Cultural, 2003. 